\title{
Functional analysis of yersiniabactin transport genes of Yersinia enterocolitica
}

Max von PettenkoferInstitut für Hygiene und Medizinische Mikrobiologie, Pettenkoferstr. 9a, 80336 München, Germany

\author{
D. Brem, C. Pelludat, A. Rakin, C. A. Jacobi and J. Heesemann
}

Author for correspondence: J. Heesemann. Tel: +49 8951605200 . Fax: +498951605202. e-mail: heesemann@m3401.mpk.med.uni-muenchen.de

\begin{abstract}
Yersinia enterocolitica 0:8, biogroup (BG) IB, strain WA-C carries a highpathogenicity island (HPI) including iron-repressible genes (irp 1-9, fyuA) for biosynthesis and uptake of the siderophore yersiniabactin (Ybt). The authors report the functional analysis of irp6,7,8, which show 98-99\% similarity to the corresponding genes $y b t P, Q, X$ on the HPI of Yersinia pestis. It was demonstrated that irp6,7 are involved in ferric (Fe)-Ybt utilization and mouse virulence of $Y$. enterocolitica, thus confirming corresponding results for $Y$. pestis. Additionally it was shown that inactivation of the ampG-like gene irp8 did not affect either Fe-Ybt utilization or mouse virulence. To determine whether irp6, irp7 and fyuA (encoding the outer-membrane Fe-Ybt/pesticin receptor FyuA) are sufficient to mediate Fe-Ybt transport/utilization, these genes were transferred into Escherichia coli ent $D, F$ and into non-pathogenic $Y$. enterocolitica, BG IA, strain NF-O. Surprisingly, $E$. coli entD, $F$ but not $Y$. enterocolitica NF-O gained the capability to utilize exogenous Fe-Ybt as a result of this gene transfer, although both strains expressed functional FyuA (pesticin sensitivity). These results suggest that besides irp6, irp7 and fyuA, additional genes are required for sufficient Fe-Ybt transport/utilization. Finally, it was shown that irp6, irp7 and fyuA but not irp8 are involved in controlling Ybt biosynthesis and fyuA gene expression: irp6 and/or irp7 mutation leads to upregulation whereas fyuA mutation leads to downregulation. However, fyuAdependent control of Ybt biosynthesis could be bypassed in a fyuA mutant by ingredients of chrome azurol S (CAS) siderophore indicator agar.
\end{abstract}

Keywords: high pathogenicity island, siderophore, iron-repressible protein, Escherichia coli

\section{INTRODUCTION}

The genus Yersinia can be divided into non-pathogenic yersiniae (Yersinia enterocolitica biogroup 1A) and two pathogroups with respect to mouse virulence (Brubaker, 1991; Perry \& Fetherston, 1997) : the high-pathogenicity (HP) group comprising Yersinia pestis, Yersinia pseudotuberculosis and Y. enterocolitica biogroup (BG) 1B, and the low-pathogenicity (LP) group of Y. enterocolitica BGs 2-5. In contrast to the non-pathogenic group both pathogroups harbour the virulence plasmid

Abbreviations: $B G$, biogroup; $C A S$, chrome azurol $S$; $D F O B$ desferrioxamine $B$; EDDHA, ethylenediamine-di(o-hydroxyphenylacetic acid); Fur, ferric uptake regulator; GFP, green fluorescent protein; HDTMA, $\mathrm{N}$-cetyl- $\mathrm{N}, \mathrm{N}, \mathrm{N}$-trimethylammonium bromide; HPI, high-pathogenicity island; TTC, 2,3,5-triphenyltetrazolium chloride; Ybt, yersiniabactin.
pYV. However, members of the HP group additionally carry the high-pathogenicity island (HPI) (Carniel et al., 1996).

The HPI consists of a conserved core region and an ATrich variable part (Rakin et al., 1999a). The core part comprises genes for the biosynthesis of the siderophore yersiniabactin (Ybt), the uptake of ferric yersiniabactin ( $\mathrm{Fe}-\mathrm{Ybt})$, the AraC-like regulator $\mathrm{YbtA}$ and the integrase of the HPI (Bearden et al., 1997; Buchrieser et al., 1999; Fetherston et al., 1999; Pelludat et al., 1998; Rakin et al., 1999a, b). Core genes are negatively regulated by the $\mathrm{Fe}^{2+}-$ Fur complex (Carniel et al., 1992; Heesemann et al., 1993; Staggs et al., 1994) and positively by the HPI-encoded transcriptional activator YbtA and presumably Fe-Ybt (Fetherston et al., 1996).

Two evolutionary lineages of HPI have been identified: the Yen HPI of Y. enterocolitica BG 1B, and the Yps HPI 
Table 1. Bacterial strains and plasmids

\begin{tabular}{|c|c|c|}
\hline Strain or plasmid & Genotype/phenotype & Reference or source \\
\hline \multicolumn{3}{|l|}{ E. coli } \\
\hline $\mathrm{DH} 5 \alpha$ & $\begin{array}{l}\text { supE44 } \Delta \text { lacU169 ( } \phi 80 \text { lacZ } \Delta \mathrm{M} 15) \text { hsdR17 recA1 endA1 gyrA96 } \\
\text { thi-1 relA1 }\end{array}$ & Hanahan (1983) \\
\hline S17-1 $\lambda$ pir & $\mathrm{Tp}^{\mathrm{r}} \mathrm{Sm}^{\mathrm{r}}$ recA thi pro hsdR ${ }^{-} M^{+}\left[\mathrm{RP} 4-2-\mathrm{Tc}:: \mathrm{Mu}: \mathrm{Kan}^{\mathrm{r}} \mathrm{Tn} 7\right) \lambda$ pir & $\begin{array}{l}\text { Miller \& Mekalanos (1988); Simon } \\
\text { et al. (1988) }\end{array}$ \\
\hline SM10 $\lambda$ pir & $\mathrm{Km}^{\mathrm{r}}$ thi-1 thr leu tonA lacY supE recA:: RP4-2-Tc: : Mu $\lambda$ pir & Miller \& Mekalanos (1988) \\
\hline MOSBlue & $\begin{array}{l}\text { endA1 hsdR17 }\left(\mathrm{r}_{\mathrm{k} 12}^{-} \mathrm{m}_{\mathrm{k} 12}^{+}\right) \text {supE44 thi-1 recA1 gyrA96 relA1 lac } \\
{\left[\mathrm{F}^{\prime} \text { pro } \mathrm{A}^{+} \mathrm{B}^{+} \text {lacl }{ }^{\mathrm{q}} \mathrm{Z} \Delta \mathrm{M} 15: \operatorname{Tn} 10\left(\mathrm{Tc}^{\mathrm{r}}\right)\right]}\end{array}$ & Amersham \\
\hline H1884 & ent $D, F$ & K. Hantke \\
\hline \multicolumn{3}{|l|}{ Y. enterocolitica } \\
\hline NF-O & Clinical isolate, serotype $\mathrm{O}: 5$; biogroup $1 \mathrm{~A}$ & Heesemann (1987) \\
\hline WA-C & $\begin{array}{l}\text { Plasmidless derivative of strain WA-314, serotype O:8, biogroup } \\
\text { 1B; spontaneous } \mathrm{Nal}^{\mathrm{r}} \text { mutant }\end{array}$ & Heesemann (1987) \\
\hline WA-CS & Spontaneous $\mathrm{Sm}^{\mathrm{r}}$ mutant derived from WA-C, $\mathrm{Nal}^{\mathrm{r}}$ & Pelludat et al. (1998) \\
\hline WA-CS $\operatorname{irp} 1:: \operatorname{Kan}^{\mathrm{r}}$ & irp1 mutant of WA-CS, Nal ${ }^{r} \mathrm{Sm}^{\mathrm{r}} \mathrm{Kan}^{\mathrm{r}}$ & Pelludat et al. (1998) \\
\hline WA-C $\Delta \operatorname{irp} 6$ & irp6 in-frame deletion mutant of WA-C, $\mathrm{Nal}^{\mathrm{r}}$ & This study \\
\hline WA-C $\Delta i r p 7$ & $\operatorname{irp} 7$ in-frame deletion mutant of WA-C, $\mathrm{Nal}^{\mathrm{r}}$ & This study \\
\hline WA-CS $\operatorname{irp} 7:: \operatorname{Kan}^{\mathrm{r}}$ & $\operatorname{irp} 7$ insertion mutant of WA-CS, $\mathrm{Nal}^{\mathrm{r}} \mathrm{Sm}^{\mathrm{r}} \mathrm{Kan}^{\mathrm{r}}$ & This study \\
\hline WA-C $\Delta \operatorname{irp} 6, \operatorname{irp} 7$ & irp6, irp7 in-frame deletion mutant of WA-C, $\mathrm{Nal}^{\mathrm{r}}$ & This study \\
\hline WA-CS $\Delta i r p 6, i r p 7$ & Spontaneous $\mathrm{Sm}^{\mathrm{r}}$ mutant derived from WA-C $\Delta \operatorname{irp} 6, \operatorname{irp} 7, \mathrm{Nal}^{\mathrm{r}}$ & This study \\
\hline $\begin{array}{l}\text { WA-CS } \Delta i r p 6, i r p 7 \\
\operatorname{irp} 1:: \operatorname{Kan}^{\mathrm{r}}\end{array}$ & $\operatorname{irp1}$, irp6, irp7 mutant of WA-CS, Nal ${ }^{\mathrm{r}} \mathrm{Sm}^{\mathrm{r}} \mathrm{Kan}^{\mathrm{r}}$ & This study \\
\hline WA-CS $\operatorname{irp} 8:: \mathrm{Kan}^{\mathrm{r}}$ & irp8 mutant of WA-CS, $\mathrm{Nal}^{\mathrm{r}} \mathrm{Sm}^{\mathrm{r}} \mathrm{Kan}^{\mathrm{r}}$ & This study \\
\hline $\begin{array}{l}\text { WA-CS } \Delta i r p 6, \operatorname{irp} 7 \text {, } \\
\operatorname{irp} 8:: \operatorname{Kan}^{\mathrm{r}}\end{array}$ & irp6, irp7, irp8 mutant of WA-CS, $\mathrm{Nal}^{\mathrm{r}} \mathrm{Sm}^{\mathrm{r}} \mathrm{Kan}^{\mathrm{r}}$ & This study \\
\hline WA $f y u A 2$ & fyuA mutant of WA-CS, Nal ${ }^{r} \mathrm{Sm}^{\mathrm{r}} \mathrm{Kan}^{\mathrm{r}}$ & This study \\
\hline \multicolumn{3}{|l|}{ Plasmids } \\
\hline pRK290B8-5::pO: 8 & Cointegrate & Heesemann \& Laufs (1983) \\
\hline pLAFR2 & $\mathrm{Tc}^{\mathrm{r}} \mathrm{Mob}^{+}$ & Friedmann et al. (1982) \\
\hline $12 \mathrm{H} 2$ & $\begin{array}{l}\text { pLAFR } 2 \text { carrying a DNA insert of WA-C encompassing } \\
\text { irp6-irp } 9 \text { operon, } y b t A \text { and } i r p 2, \mathrm{Tc}^{\mathrm{r}}\end{array}$ & Rakin \& Heesemann (1995) \\
\hline pMOSBlue & Cloning vector, $\mathrm{Ap}^{\mathrm{r}}$ & Amersham \\
\hline pMOS1.1 & $\begin{array}{l}\text { pMOSBlue containing ybtA6507-S360 PCR fragment with a } \\
465 \text { bp deletion between the NruI sites, Ap }{ }^{r}\end{array}$ & This study \\
\hline pMOS2.4 & pMOSBlue containing S368-ybtA355 PCR fragment, Ap ${ }^{r}$ & This study \\
\hline pMOS2.0 & $\begin{array}{l}\text { pMOSBlue containing ybtA355-S368 PCR fragment with a } \\
402 \text { bp deletion between the EcoRV sites, } A^{r}{ }^{r}\end{array}$ & This study \\
\hline pMOS1.2 & $\begin{array}{l}\text { pMOSBlue containing S452-8354Eco PCR fragment with a } \\
2313 \text { bp deletion between the NruI and EcoRV sites, Ap }{ }^{r}\end{array}$ & This study \\
\hline pMOS $\operatorname{irp} 7:: \operatorname{Kan}^{\mathrm{r}}$ & $\begin{array}{l}\text { pMOSBlue containing S368-ybtA355 PCR fragment with a } \\
\text { kanamycin cassette inserted into NruI site, } \mathrm{Ap}^{\mathrm{r}} \mathrm{Kan}^{\mathrm{r}}\end{array}$ & This study \\
\hline pBAD18 & Cloning vector, $\mathrm{Ap}^{\mathrm{r}}$ & Guzman et al. (1995) \\
\hline pBAD $\operatorname{irp} 8:: \operatorname{Kan}^{\mathrm{r}}$ & $\begin{array}{l}\text { pBAD18 containing irp8Xba-irp8Hind PCR fragment with a } \\
\text { kanamycin cassette inserted into } S p h \mathrm{I} \text { site, } \mathrm{Ap}^{\mathrm{r}} \mathrm{Kan}^{\mathrm{r}}\end{array}$ & This study \\
\hline pKNG101 & Suicide vector with $s a c B R$ genes, $\mathrm{Sm}^{\mathrm{r}}$ & Kaniga et al. (1991) \\
\hline pKNG1.1 & pKNG101 containing BamHI-XbaI fragment of pMOS1.1, Sm ${ }^{\mathrm{r}}$ & This study \\
\hline pKNG2.0 & pKNG101 containing BamHI-XbaI fragment of pMOS2.0, $\mathrm{Sm}^{\mathrm{r}}$ & This study \\
\hline pKNG1.2 & pKNG101 containing BamHI-XbaI fragment of pMOS1.2, $\mathrm{Sm}^{\mathrm{r}}$ & This study \\
\hline pKAS32 & Suicide vector with $r p s L$ gene, $\mathrm{Ap}^{\mathrm{r}}$ & Skorupski \& Taylor (1996) \\
\hline pKAS $i r p 7:: \operatorname{Kan}^{r}$ & $\begin{array}{l}\text { pKAS32 containing XbaI-SacI fragment of pMOS irp7::Kan }{ }^{r} \text {, } \\
\operatorname{Ap}^{r} \operatorname{Kan}^{r}\end{array}$ & This study \\
\hline
\end{tabular}


Table 1 (cont.)

\begin{tabular}{|c|c|c|}
\hline Strain or plasmid & Genotype/phenotype & Reference or source \\
\hline pKAS $\operatorname{irp} 8:: \operatorname{Kan}^{\mathrm{r}}$ & $\begin{array}{l}\text { pKAS32 containing irp8Xba-irp8Bam PCR fragment of pBAD } \\
\text { irp8:: } \operatorname{Kan}^{r}, A^{r} \operatorname{Kan}^{r}\end{array}$ & This study \\
\hline pKAS-E1Kan & $\begin{array}{l}\text { pKAS } 32 \text { containing EcoRI-SalI fragment of irp1 with a } \\
\text { kanamycin cassette (without transcriptional terminator) } \\
\text { inserted into EcoRV site, } A^{r}{ }^{r} \operatorname{Kan}^{r}\end{array}$ & Pelludat et al. (1998) \\
\hline pSVfyuA & $\begin{array}{l}\text { pKAS32 containing } 3 \cdot 3 \mathrm{~kb} \text { EcoRI fragment with a kanamycin } \\
\text { cassette inserted into } S p h \text { I site of } f y u A, A^{r} \operatorname{Kan}^{r}\end{array}$ & This study \\
\hline pSB315 & $\begin{array}{l}\text { Containing kanamycin cassette without transcriptional } \\
\text { terminator, } \operatorname{Ap}^{r} \operatorname{Kan}^{r}\end{array}$ & Galan et al. (1992) \\
\hline pT7-5 & Cloning vector, $\mathrm{Ap}^{\mathrm{r}}$ & Tabor \& Richardson (1985) \\
\hline pHM6 & pT7-5 with fyuA, Ap ${ }^{\mathrm{r}}$ & Rakin et al. (1994) \\
\hline pACYC184 & Cloning vector, $\mathrm{Cm}^{\mathrm{r}} \mathrm{Tet}^{\mathrm{r}}$ & Chang \& Cohen (1978) \\
\hline pCJFY5G3 & $\begin{array}{l}\text { fyuA5-gfp } 3 \text { fragment ( } 153 \mathrm{bp} \text { of the } f y u A \text { promoter region and } 5 \\
\text { codons of } f y u A \text { fused to } g f p 3 \text { ) cloned into pACYC184 }\end{array}$ & Jacobi (1999) \\
\hline pACYC5.1 & $\begin{array}{l}5 \cdot 1 \mathrm{~kb} S p h \mathrm{I} \text { fragment of } 12 \mathrm{H} 2 \text { encompassing } \operatorname{irp} 6 \text { and } \operatorname{irp} 7 \text { cloned } \\
\text { into pACYC } 184, \mathrm{Cm}^{\mathrm{r}}\end{array}$ & This study \\
\hline pACYC5.2 & $\begin{array}{l}2.6 \mathrm{~kb} X b a \mathrm{I}-H i n \mathrm{dIII} \text { fragment of pHM6 encompassing fyuA } \\
\text { cloned into pACYC5.1, } \mathrm{Cm}^{\mathrm{r}}\end{array}$ & This study \\
\hline pHM10 & pACYC184 with fyuA, $\mathrm{Cm}^{\mathrm{r}}$ & Rakin et al. (1994) \\
\hline pGEX-4T-3 & $\mathrm{Ap}^{\mathrm{r}}, g s t$ & Pharmacia \\
\hline pGEX irp6 & $\begin{array}{l}\text { pGEX-4T-3 containing 8301Bam-6515Sma PCR product (irp6), } \\
\text { Ap }^{\mathrm{r}}\end{array}$ & This study \\
\hline pGEX $\operatorname{irp} 7$ & $\begin{array}{l}\text { pGEX-4T-3 containing 6509Bam-4727Sma PCR product (irp7), } \\
\text { Ap }^{\mathrm{r}}\end{array}$ & This study \\
\hline
\end{tabular}

of Y. pestis and Y. pseudotuberculosis. These HPIs have high homology within the core gene sequences but unrelated AT-rich parts (Rakin et al., 1995, 1999a). In Yps HPI the four core genes $y b t P, y b t Q, y b t X$ and $y b t S$ constitute a polycistronic operon. It has been demonstrated that YbtP and $\mathrm{YbtQ}$ are involved in Fe- $\mathrm{Ybt}$ uptake and supposedly form a heterodimeric ABC transporter (Fetherston et al., 1999). YbtS participates in Ybt biosynthesis. YbtX shows homology to AmpG, which is proposed to act as a signal transducer or permease in the $\beta$-lactamase induction system (Lindquist et al., 1993). The function of $\mathrm{YbtX}$ and its role in virulence are still unknown (Fetherston et al., 1999; Gehring et al., 1998). A similar operon (irp6, irp7, irp8 and $i r p 9)$ has been described for Y. enterocolitica with 98-99\% homology to the corresponding sequences of $Y$. pestis (Rakin et al., 1999a).

In principle, siderophore utilization by Gram-negative bacteria requires genes encoding (i) a TonB-dependent uptake system for transport through the outer membrane including a high-affinity siderophore-specific receptor, (ii) a periplasmic-binding-protein-dependent transport (PBT) system including a periplasmic binding protein and an ABC transporter for transfer from periplasm to cytoplasm, and (iii) proteins capable of releasing siderophore-bound iron (e.g. siderophore reductase/esterase) (Earhart, 1996; Boos \& Lucht, 1996; Schubert et al., 1999; Braun et al., 1998). However, no gene encoding a periplasmic binding protein or a protein releasing iron from $\mathrm{Fe}-\mathrm{Y}$ bt has been detected so far within the HPI, suggesting that such genes might be located outside the HPI or are not required.

In spite of the high degree of similarity between Yen HPI and Yps HPI, significant HPI-associated differences between $Y$. pestis and $Y$. enterocolitica have been reported. (i) On CAS siderophore indicator agar $Y$. enterocolitica produces haloes whereas $Y$. pestis does not (Rakin et al., 1999a). (ii) Y. pestis requires the functional Ybt system for mouse virulence when mice are challenged subcutanously but can go without HPI when the bacteria are injected intravenously (Une \& Brubaker, 1984; Bearden et al., 1997; Fetherston et al., 1999). In contrast, a fyuA mutant of Y. enterocolitica $\mathrm{O}: 8$ and an irp2 mutant of $Y$. pseudotuberculosis (enteropathogenic Yersinia species) are highly attenuated for mice when the animals are challenged intravenously or orally (Carniel et al., 1992; Rakin et al., 1994). (iii) The promoter region of irp6-9 and $y b t A$ of Yen HPI but not of Yps HPI carries an ERIC insertion which might have an influence on the regulation of these genes (Rakin et al., 1999a). These HPI-associated differences between $Y$. pestis and Y. enterocolitica, the unusual Fe-Ybt transport system composed of FyuA, Irp6 and Irp7, and the unknown function of Irp8 prompted us to characterize $\operatorname{irp} 6, \operatorname{irp} 7, \operatorname{irp} 8$ and $f y u A$ of $Y$. enterocolitica $\mathrm{O}: 8$ strain WA-C with respect to mouse virulence, Fe-Ybt transport/utilization, Ybt production and Ybt-induced upregulation of $f y u A$. 


\section{METHODS}

Bacterial strains and plasmids. The bacterial strains and plasmids used in the study are listed in Table 1. Strains were grown in Luria-Bertani (LB) broth or on LB agar plates (Difco) at $28^{\circ} \mathrm{C}$ (Y. enterocolitica) or $37^{\circ} \mathrm{C}$ (Escherichia coli). For iron-deficient growth, strains were cultivated in NBD liquid medium [nutrient broth (Difco) supplemented with $5 \mathrm{~g} \mathrm{NaCl} \mathrm{l}^{-1}$ (NB) and $200 \mu \mathrm{M} \alpha, \alpha^{\prime}$-dipyridyl (Sigma)]. Blood agar plates were used for bacterial conjugation. Antibiotics were added to the following concentrations: nalidixic acid and streptomycin, $100 \mu \mathrm{g} \mathrm{ml}^{-1}$; kanamycin, $40 \mu \mathrm{g} \mathrm{ml}^{-1}$; tetracycline, $10 \mu \mathrm{g} \mathrm{ml}^{-1}$; chloramphenicol, $20 \mu \mathrm{g} \mathrm{ml}^{-1}$; ampicillin, $100 \mu \mathrm{g} \mathrm{ml}^{-1}$ for E. coli and $500 \mu \mathrm{g} \mathrm{ml}^{-1}$ for Y. enterocolitica.

Spontaneous streptomycin-resistant $\left(\mathrm{Sm}^{\mathrm{r}}\right)$ colonies of WA-C $\Delta$ irp6,irp7 (Table 1) were selected by stepwise increments of streptomycin $\left(10,30,50,70\right.$ and $\left.100 \mu \mathrm{g} \mathrm{ml}^{-1}\right)$ in LB medium. The resulting mutant was designated WA-CS $\Delta$ irp6,irp7.

DNA techniques. Plasmids were isolated by the alkaline lysis method and introduced into E. coli and Y. enterocolitica by electroporation (Gene Pulse Apparatus, Bio-Rad) according to the manufacturer's instructions. PCR was performed in an automated thermal cycler (Gene Amp PCR System 2400; Perkin-Elmer) as described previously (Rakin et al., 1999a) with the TaqI polymerase and different pairs of oligonucleotides (Metabion) (Table 2). The initial denaturation step $\left(94^{\circ} \mathrm{C}, 7 \mathrm{~min}\right.$ ) was followed by 25 cycles of denaturation $\left(94^{\circ} \mathrm{C}\right)$, annealing and extension $\left(72^{\circ} \mathrm{C}\right)$, with one final extension step $\left(72^{\circ} \mathrm{C}, 7 \mathrm{~min}\right)$. Annealing temperatures were set according to the primers used.

Construction of mutants. Suicide vector pKNG101 (Table 1) was used for the construction of deletion mutants by reverse genetics. pKNG101 contains an R6K origin of replication that requires the pir gene product, str $A B$ encoding streptomycin phosphotransferase and the $s a c A B$ genes from Bacillus subtilis, which render bacterial strains sensitive to sucrose. Integration of the suicide vector results in a streptomycin-resistant and sucrose-sensitive phenotype. Sucrose resistance $\left(S_{u c}{ }^{r}\right)$ and streptomycin sensitivity $\left(\mathrm{Sm}^{\mathrm{s}}\right)$ arise after an allelic exchange with concomitant loss of the vector.

To construct the irp6 in-frame deletion mutant WA-C $\Delta$ irp6, the ybtA6507-S360 (Table 2) PCR product was cloned into the blunt-ended pMOSBlue vector and the 465 bp NruI fragment was subsequently deleted (pMOS1.1). The BamHI-XbaI fragment from pMOS1.1 containing the in-frame deletion was ligated into the pKNG101 suicide vector to yield pKNG1.1 (Fig. 1).

To generate WA-C $\Delta$ irp7, the PCR product amplified with primers S368 and ybtA355 was ligated into pMOSBlue, resulting in pMOS2.4. The $402 \mathrm{bp} \mathrm{EcoRV} \mathrm{fragment} \mathrm{was}$ excised from pMOS2.4, generating pMOS2.0. The BamHIXbaI fragment of pMOS2.0 was transferred into pKNG101, resulting in pKNG2.0.

To create WA-C $\Delta$ irp6,irp7, the PCR product S452-8354Eco was ligated into pMOSBlue and the 2313 bp EcoRV-NruI fragment was deleted, generating pMOS1.2. The $1.2 \mathrm{~kb}$ BamHI-XbaI fragment from pMOS1.2 was cloned into pKNG101, resulting in pKNG1.2 (Fig. 1).

The constructs (pKNG1.1, pKNG2.0 and pKNG1.2) were transformed into E. coli SM10 ipir followed by mobilization into WA-C by conjugation.

Cells were selected on agar plates containing nalidixic acid $\left(100 \mu \mathrm{g} \mathrm{ml}^{-1}\right)$ and streptomycin $\left(100 \mu \mathrm{g} \mathrm{ml}^{-1}\right)$. Sm ${ }^{\mathrm{r}}$ clones were streaked onto LB plates with $5 \%$ sucrose. $\mathrm{Sm}^{\mathrm{s}} \mathrm{Suc}^{\mathrm{r}}$ colonies were analysed by PCR and Southern blot hybridization to identify strains containing the deletions.

pKAS32 (Table 1) contains the R6K origin of replication and the $r p s L$ gene, which encodes the $\mathrm{S} 12$ protein of the ribosomes conferring streptomycin sensitivity (dominant allele). Insertion of the suicide vector into the chromosome results in a $\mathrm{Sm}^{\mathrm{s}}$ dominant phenotype of a former $\mathrm{Sm}^{\mathrm{r}}$ strain. $\mathrm{Kan}^{\mathrm{r}} \mathrm{Sm}^{\mathrm{r}}$ derivatives arise after an allelic exchange and loss of the vector.

To generate WA-CS $\operatorname{irp} 7:: \mathrm{Kan}^{\mathrm{r}}$, a HincII-cut kanamycin cassette without transcriptional terminator was ligated into NruI-digested pMOS2.4, resulting in pMOS irp7:: Kan ${ }^{\mathrm{r}}$. The insert containing the kanamycin cassette was excised with $\mathrm{XbaI} / \mathrm{SacI}$ and inserted into the suicide vector pKAS32 (designated pKAS $\operatorname{irp} 7:: \operatorname{Kan}^{\mathrm{r}}$ ) (Fig. 1). The construct was transformed into E. coli S17-1 $\lambda$ pir followed by mobilization into WA-CS.

To create WA-CS $\operatorname{irp} 8:: \mathrm{Kan}^{\mathrm{r}}$, a PCR product (amplified with the primers irp8Xba and irp8Hind) containing the whole gene was cut with $\mathrm{XbaI}$ and HindIII and ligated into pBAD18. A

Table 2. Primers used (restriction sites underlined)

\begin{tabular}{|c|c|c|}
\hline Primer & Sequence $\mathbf{5}^{\prime}-\mathbf{3}^{\prime}$ & Comments \\
\hline ybtA6507 & TCCGCAGGATTATTGTCTTTC & End of $i r p 6$, reverse \\
\hline S360 & CATTACGCGGCTTTTCATCTG & In $\operatorname{irp} 6$, forward \\
\hline S368 & AATCCCCCTTCTCGCCCAAAC & In $\operatorname{irp} 8$, reverse \\
\hline ybtA355 & CTGACCCGGAAAACGAAGC & In irp6, forward \\
\hline S452 & CCCCGGCGATGGTGGATAAAC & In $\operatorname{irp} 7$, reverse \\
\hline 8354Eco & TTTGAATTCCTGAATTGTCGCTTTTGGTG & Start of irp6 with EcoRI restriction site, forward \\
\hline $\operatorname{irp} 8 \mathrm{Xba}$ & GCATCTAGACGTTATCAGGCGCTGTGGCAG & Start of $\operatorname{irp} 8$ with $\mathrm{XbaI}$ restriction site, forward \\
\hline irp8Hind & CGCAAGCTTTCTGTGTTATTCCCGGATCA & End of $\operatorname{irp} 8$ with HindIII restriction site, reverse \\
\hline $\operatorname{irp} 8 \mathrm{Bam}$ & AGCGGATCCTCTGTTTATTCCCGGATCA & End of $\operatorname{irp} 8$ with BamHI restriction site, reverse \\
\hline 8301Bam & GTTGGATCCATGTAATCTCAATCATC & Start of irp6 with BamHI restriction site, forward \\
\hline $6515 \mathrm{Sma}$ & ATCECCGGGATTATTGTCTTTCATTTT & End of irp6 with $S m a$ I restriction site, reverse \\
\hline $4727 \mathrm{Sma}$ & TTTCCCGGGTCACTCATGCACCCACTC & End of $i r p 7$ with $S m a$ I restriction site, reverse \\
\hline 6509Bam & TAAGGATCCATGAAAGACAATAATCCTGCG & Start of $i r p 7$ with BamHI restriction site, forward \\
\hline ybtA6451 & CCTGACTGCCAACGCTGGAGA & In $\operatorname{irp} 7$, reverse \\
\hline
\end{tabular}




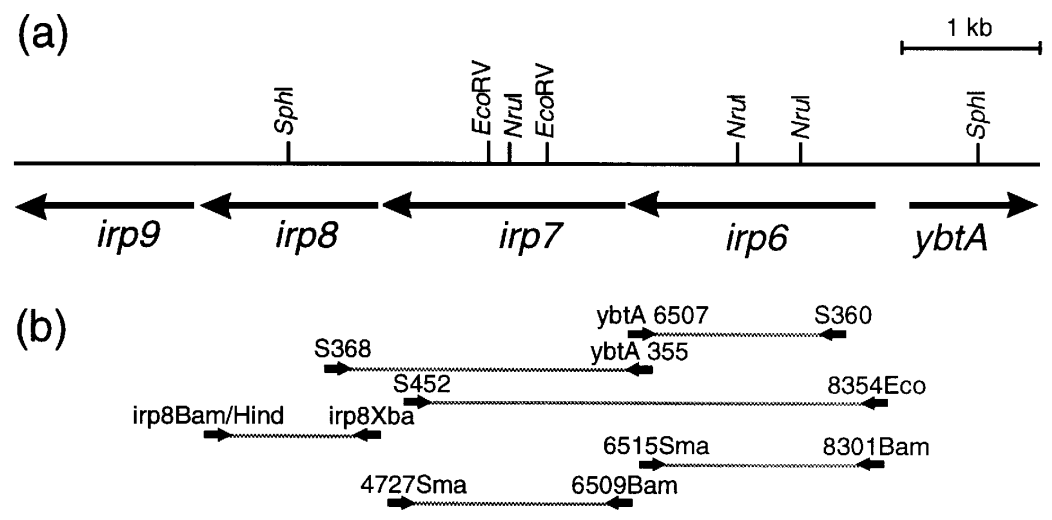

(c)

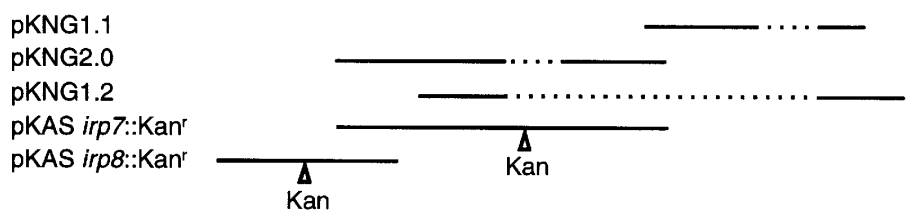

(d)

pGEXirp6

PGEXirp7

PACYC5.1

\begin{abstract}
Fig. 1. (a) Restriction sites in irp6, irp7, irp8, irp9 and ybtA used for genetic manipulations. Arrows indicate the directions of transcription. (b) Black arrows show primers used for amplification. (c) Suicide vectors used for construction of mutants. Dotted lines represent deletions, triangles sites of kanamycin cassette insertion. (d) Recombinant plasmids used for complementation.
\end{abstract}

HincII-cut kanamycin cassette lacking a transcriptional terminator was inserted into the $S p h \mathrm{I}$ site (filled-in) of $i r p 8$ (pBAD $\operatorname{irp} 8:: \operatorname{Kan}^{\mathrm{r}}$ ). irp8 containing the kanamycin cassette was amplified with irp8Xba and irp8Bam, cut with XbaI and BamHI and ligated into pKAS32, resulting in pKAS irp 8:: Kan ${ }^{\mathrm{r}}$. The construct was transformed into E. coli S17-1 ipir followed by mobilization into WA-CS and WA-CS

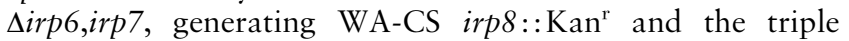
mutant WA-CS $\Delta \operatorname{irp6}, \operatorname{irp} 7, \operatorname{irp} 8:: \mathrm{Kan}^{\mathrm{r}}$.

To generate an irp6,irp7,irp1 triple mutant suicide vector pKAS-E1Kan was mobilized into double mutant WA-CS $\Delta \operatorname{irp6,irp7~(Table~1).~}$

To create mutant WA fyuA2 a $3.3 \mathrm{~kb}$ EcoRI fragment including $1.6 \mathrm{~kb}$ of $f y u A$ was inserted into vector pKS. A HincII-cut kanamycin cassette lacking a transcriptional terminator was ligated into the filled-in $S p h \mathrm{I}$ site of $f y u A$. The EcoRI fragment including the kanamycin cassette was ligated into suicide vector pKAS32. The construct was transformed into E. coli S17-1 apir followed by mobilization into WA-CS.

Mutants were selected on agar plates containing kanamycin $\left(40 \mu \mathrm{g} \mathrm{ml}^{-1}\right)$, streptomycin $\left(100 \mu \mathrm{g} \mathrm{ml}^{-1}\right)$ and nalidixic acid $\left(100 \mu \mathrm{g} \mathrm{ml}^{-1}\right)$. Correct insertions of the kanamycin cassettes were confirmed by Southern blot hybridization.

Construction of plasmids for complementation. The $5 \cdot 1 \mathrm{~kb}$ SphI fragment of plasmid 12H2 (Table 1) carrying irp6 and irp7 and the promoter of the irp6-irp9 operon was subcloned into pACYC184, resulting in pACYC5.1 (Fig. 1). pACYC5.2 additionally contains a $2.6 \mathrm{~kb} \mathrm{XbaI}-H$ indIII fragment of pHM6 harbouring the $f y u A$ receptor gene (Table 1).

irp6 was amplified by PCR using primers 6515Sma and 8301Bam (Table 2) and ligated into pGEX-4T-3 downstream of gst (the glutathione $S$-transferase gene) to yield pGEXirp6 (Fig. 1). The 4727Sma-6509Bam PCR product (irp7) was cloned into pGEX-4T-3 downstream of gst, resulting in pGEXirp7.
Screening for production of iron-chelating compounds. Strains to be tested were dropped $(1 \mu \mathrm{l}$ of an overnight liquid culture) on chrome azurol S (CAS) siderophore indicator agar (Heesemann, 1987; Schwyn \& Neilands, 1987) and incubated for $2 \mathrm{~d}$ at $28^{\circ} \mathrm{C}$. A clearly visible red-orange halo around the bacteria was indicative of siderophore production (CASpositive phenotype).

Feeding assay with purified yersiniabactin, desferrioxamine $B$ and culture supernatants. Culture supernatants were obtained from yersiniae grown for $48 \mathrm{~h}$ at $28^{\circ} \mathrm{C}$ in iron-poor NBD medium. The cells were pelleted by centrifugation and the supernatants were sterilized by filtration and used for feeding experiments. Desferrioxamine B (DFOB) (Desferal) was obtained from Ciba Geigy. Purified yersiniabactin was kindly provided by R. Reissbrodt (Wernigerode, Germany). For testing of siderophore utilization, bacteria were seeded in CDM-H agar (Flossmann et al., 1985) rendered iron-deficient by addition of the chelator EDDHA. Filter papers soaked with siderophore-containing culture supernatant, Ybt or DFOB were placed on the agar layer. Bacteria were cultivated at $37^{\circ} \mathrm{C}$ (E. coli) or $28^{\circ} \mathrm{C}$ (Y. enterocolitica) for $16 \mathrm{~h}$ and colonies were visualized by using 2,3,5-triphenyltetrazolium chloride (TTC).

Pesticin assay. The pesticin-producing strain Y. pestis EV76 was grown overnight at $28{ }^{\circ} \mathrm{C}$ and pesticin production was induced by adding mitomycin $\mathrm{C}\left(0.3 \mu \mathrm{g} \mathrm{ml}^{-1}\right)$ and incubating for an additional $16 \mathrm{~h}$. Cells were collected by centrifugation and the supernatant was used as a crude pesticin preparation after sterilization with $0 \cdot 1 \%$ chloroform (Hu et al., 1972).

The pesticin assay was performed as described by Heesemann et al. (1993). CDM-H plates without addition of EDDHA were overlaid with $0.6 \%$ agar containing $10^{7}$ bacteria from mid-exponential culture (double-layer technique). Ten microlitres of pesticin-containing culture supernatant was dropped on these plates followed by incubation at $37^{\circ} \mathrm{C}$ for $16 \mathrm{~h}$. Lysis zones were visualized by staining with TTC. 
SDS-PAGE and immunoblotting. Bacteria were grown overnight in iron-limited CDM-H liquid medium, centrifuged, washed, and solubilized by boiling in Laemmli buffer (total cell lysate) (Laemmli, 1970). Equal amounts of all strains were separated on a $10 \%$ SDS-polyacrylamide gel (SDS-PAGE) and for immunoblotting, transferred electrophoretically to nitrocellulose membranes (BA85; Schleicher \& Schüll) (Heesemann et al., 1986). For immunostaining, a rabbit anti-FyuA antiserum (Heesemann et al., 1993) (1:1000) and a peroxidaseconjugated secondary anti-rabbit antibody $(1: 5000)$ were used for chemiluminescence detection (ECL kit from Amersham).

RNA isolation and RT-PCR. Strains were grown in CDM-H liquid medium to an $\mathrm{OD}_{600}$ of $0 \cdot 5$. Total cellular RNA was isolated as recommended by the manufacturer (High Pure RNA Isolation Kit; Boehringer Mannheim). DNA was digested by incubation with 2 U RNase-free DNase (Promega) for $30 \mathrm{~min}$ at $37^{\circ} \mathrm{C}$. DNase was heat-inactivated at $75^{\circ} \mathrm{C}$ for $10 \mathrm{~min}$. RT-PCR was performed with a Reverse ${ }^{\mathrm{i}} \mathrm{T}$ 1st strand synthesis kit (Advanced Biotechnologies) according to the manufacturer's instructions. Products were analysed by loading $10 \mu \mathrm{l}$ of the PCR mixture onto a $1.5 \%$ agarose gel.

GFP reporter gene studies. The plasmid pCJFY5G3 (Jacobi, 1999) containing $153 \mathrm{bp}$ of the fyuA promoter region (Rakin et al., 1994) and five codons of $f y u A$ fused to $g f p 3$ (encoding green fluorescent protein: Jacobi et al., 1998; Schubert et al., 2000) was transferred into WA-C, WA-C $\Delta \operatorname{irp} 6$,irp7, WA-CS $\operatorname{irp} 8:: \mathrm{Kan}^{\mathrm{r}}$, WA-CS $\Delta \operatorname{irp} 6, \operatorname{irp} 7, \operatorname{irp} 8:: \mathrm{Kan}^{\mathrm{r}}$, WA fyuA2 and WA-CS $\operatorname{irp} 1:: \operatorname{Kan}^{\mathrm{r}}$ by electroporation (Table 1 ). Cells were grown in NB or NBD liquid medium or on CAS agar, and fluorescence was measured after $24 \mathrm{~h}$.

Flow-cytometric measurements were performed with a Coulter Epics Flow cytometer equipped with an argon $488 \mathrm{~nm}$ laser. Bacteria were diluted as required and detected by side scatter as described previously (Pelludat et al., 1998). The scale was logarithmic, and fluorescence and scatter data were collected for 50000 bacteria.

Virulence testing. For testing mouse-virulence the mobilizable cointegrate pRK290B8-5 ::pO: 8 (Heesemann \& Laufs, 1983), containing the virulence plasmid (pYVO:8) of Y. enterocolitica O:8 was introduced into WA-C and derivatives of WA-C. The exconjugants were mouse-passaged, resulting in cointegrate dissociation and selection for pYVO:8-carrying strains. BALB/c mice were challenged intravenously with $5 \times 10^{6}$ c.f.u. of mouse-passaged WA-C(pYVO:8), WA-C $\Delta \operatorname{irp6}$ irp7(pYVO:8), WA-CS(pYVO:8) and WA-CS $\operatorname{irp} 8:: \operatorname{Kan}^{\mathrm{r}}(\mathrm{pYVO}: 8)$. On day 2 post-infection, mice were killed. Spleen and liver were removed and homogenized in
$1 \mathrm{ml}$ and $5 \mathrm{ml}$, respectively, of sterile PBS containing $0.5 \%$ Tergitol and $0.5 \%$ bovine serum albumin by the use of tissue homogenizers. Homogenates were plated on LB agar and the number of bacteria in spleen and liver was determined.

\section{RESULTS}

\section{Role of irp6, irp7 and irp8 in Fe-Ybt utilization in Y. enterocolitica 0:8}

To investigate the function of $i r p 6, \operatorname{irp} 7$ and $\operatorname{irp} 8$ in $Y$. enterocolitica $\mathrm{O}: 8$, different mutants were constructed (Table 1, Fig. 1).

Contribution of $\operatorname{irp} 6$, irp7 and $\operatorname{irp} 8$ to Fe-Ybt uptake was shown by seeding the different mutants into iron-limited $\mathrm{CDM}-\mathrm{H}$ agar and feeding from $\mathrm{Fe}-\mathrm{Ybt}$ containing filter disks. Fe-Ybt supported the growth of WA-C, WA-CS and WA-CS $\operatorname{irp} 8:: \mathrm{Kan}^{\mathrm{r}}$ but not of the $\operatorname{irp} 6$ and $\operatorname{irp} 7$ single (WA-C $\Delta i r p 6$, WA-C $\Delta i r p 7$, WA-CS $i r p 7:: \operatorname{Kan}^{\mathrm{r}}$ ), irp6,irp7 double (WA-C $\Delta$ irp6,irp7), irp6,irp7,irp8 triple (WA-CS $\Delta i r p 6, i r p 7, \operatorname{irp} 8:: \operatorname{Kan}^{\mathrm{r}}$ ) mutants or the fyuA (WA fyuA2) mutant (Fig. 2a). In contrast, filter disks with DFOB promoted growth of all strains in CDM-H agar, indicating functional TonB-dependent ferric hydroxamate transport (control test).

The irp6 and irp7 mutants were successfully complemented in Fe-Ybt-supported growth by plasmids pGEXirp6 (for irp6 mutant) and pGEXirp7 (for irp7 mutants) even without addition of IPTG (probably due to incomplete repression). Cross-complementation of the irp7 mutant by the functional irp6 gene and vice

Table 3. Numbers of c.f.u. in spleen and liver of infected mice

\begin{tabular}{|lll|}
\hline $\begin{array}{l}\text { Strain with pYVO:8 } \\
\text { plasmid }\end{array}$ & Spleen & Liver \\
\hline WA-C & $2 \cdot 7 \times 10^{7}$ & $4 \cdot 5 \times 10^{6}$ \\
WA-C $\Delta$ irp6, irp7 & $2 \cdot 7 \times 10^{2}$ & $1 \cdot 3 \times 10^{3}$ \\
WA-CS & $1 \cdot 1 \times 10^{8}$ & $4 \cdot 1 \times 10^{6}$ \\
WA-CS $i r p 8::$ Kan $^{\mathrm{r}}$ & $3 \cdot 3 \times 10^{7}$ & $7 \cdot 5 \times 10^{7}$ \\
\hline
\end{tabular}

(a)

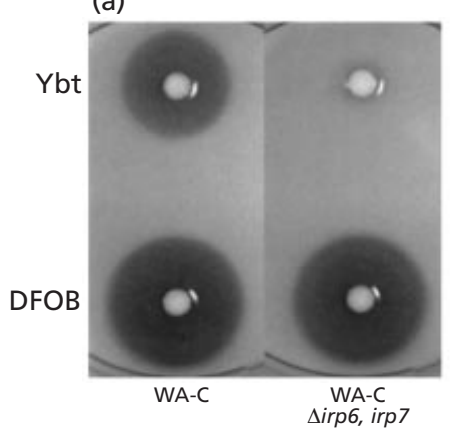

(b)

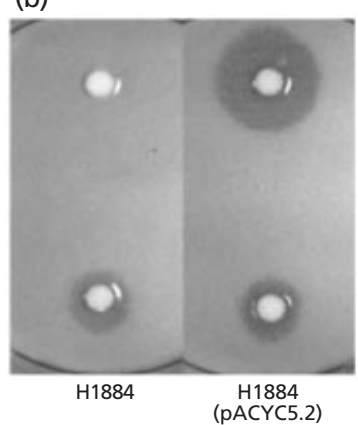

(c)

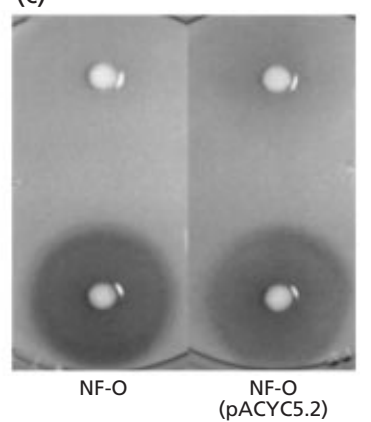

Fig. 2. Feeding assay for strains seeded in CDM-H agar with Ybt or DFOB. (a) Y. enterocolitica O:8 strains WA-C and WAC $\Delta$ irp6,irp7. (b) E. coli entD,F strains $\mathrm{H} 1884$ and H1884(pACYC5.2). (c) Y. enterocolitica O:5, NF-O and NF-O(pACYC5.2). 
(a)

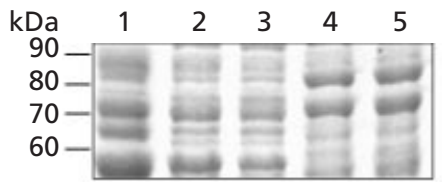

(b)

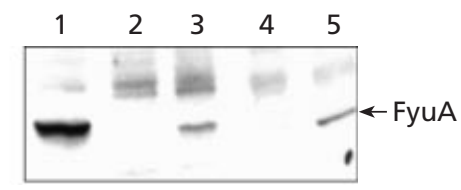

Fig. 3. Detection of FyuA: (a) SDS-PAGE $(10 \%)$ and (b) corresponding immunoblot using FyuA antibody. Cell lysates of $Y$. enterocolitica WA-C (lane 1), NF-O (lane 2), NF-O(pACYC5.2) (lane 3), E. coli entD, $F$, strain H1884 (lane 4), H1884(pACYC5.2) (lane 5). Arrow indicates FyuA protein. versa was inefficient. The fyuA mutant was complemented by introduction of plasmid pHM10 carrying fyuA.

These results clearly show that fyuA, irp6 and irp7 but not irp 8 are involved in Fe-Ybt uptake/utilization of $Y$. enterocolitica $\mathrm{O}: 8$.

\section{Influence of irp6, irp7, and irp8 on mouse virulence}

To investigate the influence of $i r p 6$, irp7 and irp8 on mouse virulence three $\mathrm{BALB} / \mathrm{c}$ mice were injected intravenously with $5 \times 10^{6}$ c.f.u. of WA-C(pYVO:8), WA-C $\Delta \operatorname{irp} 6, \operatorname{irp} 7(\mathrm{pYVO}: 8)$, WA-CS(pYVO:8) and

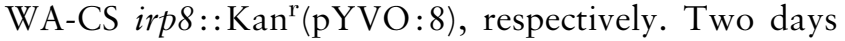
post-infection mice were killed and bacteria in spleen and liver were counted. The number of c.f.u. from the spleens of mice infected with WA-C(pYVO:8) was $2 \cdot 7 \times 10^{7}$ per spleen, $10^{5}$-fold higher than in spleens of mice infected with the irp6,irp7 double mutant $\left(2.7 \times 10^{2}\right)$. The difference in c.f.u. per liver between parental and mutant strain was $10^{3}$ (Table 3 ). Three additional mice infected with WA-C $\Delta$ irp6,irp7 (pYVO:8), were killed $10 \mathrm{~d}$ post-infection and no bacteria could be detected in spleen and liver. In contrast, disruption of irp 8 did not decrease virulence with respect to the parental strain WA-CS(pYVO:8), as demonstrated by similar c.f.u. counts in spleen and liver (Table 3). These results indicate that the ABC transporter genes irp6 and irp 7 but not the $\operatorname{amp} G$-like irp 8 are required for mouse virulence in $Y$. enterocolitica $\mathrm{O}: 8$.

\section{irp6, irp7 and fyuA enable $E$. coli but not non- pathogenic $Y$. enterocolitica BG 1 A to utilize ferric yersiniabactin}

We considered whether irp6, irp7 and $f y u A$ may be sufficient for Fe-Ybt uptake and utilization in an E. coli entD, $F$ mutant (strain H1884 deficient in enterochelin synthesis and HPI-negative). The recombinant plasmids pACYC5.1 (carrying irp6 and irp7) and pACYC5.2 (carrying irp6, irp7 and $f y u A$ ) were able to restore FeYbt-supported growth of WA-C $\Delta$ irp6,irp7 and WA fyuA2, respectively. Plasmids carrying different combinations of transport genes were introduced into H1884 and the strains were analysed for Fe-Ybt-mediated growth support. H1884 carrying plasmids pHM10 (fyuA) or pACYC5.1 (irp6 and irp7) were not supported in growth by Fe-Ybt-soaked filters. In contrast H1884 harbouring pACYC5.2 (carrying irp6, irp7 and fyuA) grew significantly around the filter disk, indicating $\mathrm{Fe}$ Ybt-supported growth (Fig. 2b). Obviously both ABC transporters (Irp6 and Irp7) and the outer membrane
Ybt receptor (FyuA) are sufficient for Fe-Ybt uptake and utilization in E. coli. All tested E. coli transformants showed small growth zones around DFOB-soaked filters due to low-level DFOB transport mediated by FhuE, the outer-membrane receptor protein for coprogen (Sauer $e t$ al., 1990).

After introduction of pACYC5.2 (irp6, irp7, fyuA) into the non-pathogenic $Y$. enterocolitica O:5, BG $1 \mathrm{~A}$ (strain NF-O), Fe-Ybt-supported growth was investigated. In contrast to WA-C and H1884(pACYC5.2), NF-O(pACYC5.2) showed no significant growth around Fe-Ybt-soaked filters when compared to the parent NF$\mathrm{O}$ strain (Fig. 2c). Addition of DFOB resulted in large growth zones of NF-O and NF-O(pACYC5.2), indicating functional TonB transport (Bäumler \& Hantke, 1992).

To elucidate whether these Fe-Ybt feeding differences were due to different $f y u A$ expression we investigated FyuA production of Y. enterocolitica NF-O(pACYC5.2) and E. coli H1884(pACYC5.2). Equal amounts of solubilized cells were analysed by immunoblotting using anti-FyuA antiserum. WA-C was used as positive control, NF-O and $\mathrm{H} 1884$ as negative controls. The immunoblot revealed that $\mathrm{NF}-\mathrm{O}$ (pACYC5.2) and H1884(pACYC5.2) produced FyuA in equal amounts but less than WA-C (Fig. 3). Similar results were obtained with outer membrane preparations.

As FyuA is also the TonB-dependent receptor for pesticin, functionality of FyuA was investigated with respect to pesticin sensitivity. Whereas $\mathrm{H} 1884$ and NF-O were pesticin-resistant, WA-C, H1884(pACYC5.2) and $\mathrm{NF}-\mathrm{O}$ (pACYC5.2) showed lysis zones after pesticin addition, demonstrating functional FyuA in all three strains (results not shown).

To compare irp6 and irp7 transcripts, RNAs of WA-C, NF-O, NF-O(pACYC5.2), H1884 and H1884(pACYC5.2) grown in CDM-H liquid medium were isolated and RT-PCRs were performed. A primer pair (ybtA6451-ybtA355) that amplifies 350 bp (including the end of irp6 and the start of irp7) was chosen for PCR. RNA of NF-O(pACYC5.2), H1884(pACYC5.2) and the positive control WA-C revealed a RT-PCR product of $350 \mathrm{bp}$, whereas RT-PCR with RNA of NF$\mathrm{O}$ and $\mathrm{H} 1884$ turned out to be negative (Fig. 4). irp6 and irp7 are more weakly transcribed in NF-O(pACYC5.2) and H1884(pACYC5.2) than in WA-C, which might be due to the missing transcriptional activator $\mathrm{YbtA}$ in the former two strains.

In conclusion, these data demonstrate that (i) in contrast to E. coli, expression of irp6, irp7 and $f y u A$ is not 


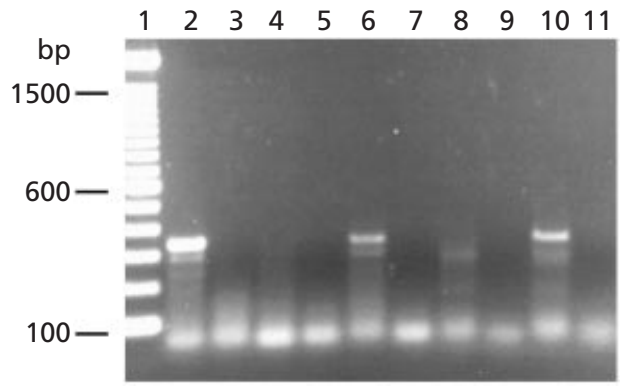

Fig. 4. Detection of irp6,irp7 transcription. RT-PCR was performed with primers (ybtA6451-ybtA355) that amplify a $350 \mathrm{bp}$ fragment overlapping irp6 and irp7. Lanes: DNA size markers (lane 1), WA-C (lanes 2 and 3), NF-O (lanes 4 and 5), NF-O(pACYC5.2) (lanes 6 and 7), H1884 (lanes 8 and 9) and H1884(pACYC5.2) (lanes 10 and 11). The RT-PCR reaction applied to lanes 2, 4, 6, 8, and 10 contained reverse transcriptase (RT), whereas reactions in lanes 3, 5, 7, 9, and 11 lacked RT and served as negative controls. sufficient for Fe-Ybt utilization in the non-pathogenic $Y$. enterocolitica O:5, BG 1A strain; and (ii) YbtA is not absolutely required for functional expression of irp6,7 and $f y u A$ in the plasmid construct pACYC5.2.

\section{Influence of irp6,7,8 and fyuA on regulation of $\mathrm{Ybt}$ production and fyu $A$ expression}

Recently, it has been suggested that the transcriptional activator $\mathrm{YbtA}$ and $\mathrm{Fe}-\mathrm{Ybt}$ or a $\mathrm{YbtA} / \mathrm{Fe}-\mathrm{Ybt}$ complex might be involved in upregulation of the Ybt biosynthesis operon irp1-5 and the Fe-Ybt receptor gene fyuA (both promoters carry repeated sequences which could serve as YbtA binding sites: Fetherston et al., 1996; Rakin et al., 1994). According to this model the Fe-Ybt transporter system Irp6,7 and FyuA mediates the $\mathrm{Fe}-\mathrm{Ybt}$ influx and thus indirectly controls the $\mathrm{Ybt}$ biosynthesis through YbtA and Fe-Ybt (see Fig. 5). Moreover, it is also conceivable that Irp8, which has

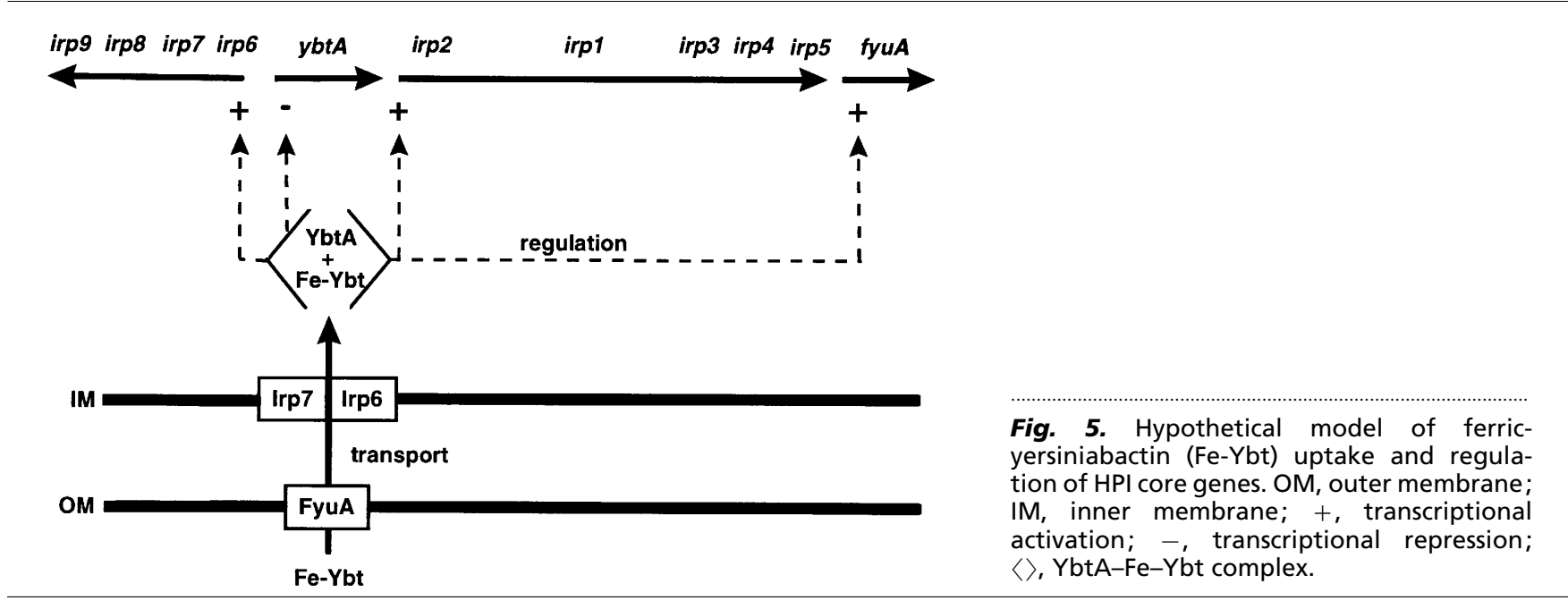

Table 4. Yersiniabactin production of $Y$. enterocolitica WA-C and mutants

\begin{tabular}{|c|c|c|c|}
\hline Strain & $\begin{array}{l}\text { Feeding of WA-CS } \\
\text { irp } 1:: \text { Kan }^{\mathrm{r}} \text { by culture } \\
\text { supernatant }\end{array}$ & $\begin{array}{l}f y u A-g f p \text { upregulation } \\
\text { in NBD medium* }\end{array}$ & CAS phenotype \\
\hline WA-C & + & + & + \\
\hline WA-C $\Delta i r p 6, i r p 7$ & + & ++ & ++ \\
\hline WA-C $\Delta i r p 6$ & + & ++ & ++ \\
\hline WA-C $\Delta i r p 7$ & + & ++ & ++ \\
\hline WA-CS $\operatorname{irp} 7:: \operatorname{Kan}^{\mathrm{r}}$ & + & ++ & ++ \\
\hline $\begin{array}{l}\text { WA-CS } \Delta i r p 6, i r p 7, \\
i r p 8:: \operatorname{Kan}^{r}\end{array}$ & + & ++ & ++ \\
\hline WA-CS $i \operatorname{rp} 8:: \operatorname{Kan}^{\mathrm{r}}$ & + & + & + \\
\hline $\begin{array}{l}\text { WA-CS } \Delta i r p 6, i r p 7 \text {, } \\
\text { irp1:: } \operatorname{Kan}^{\mathrm{r}}\end{array}$ & - & - & - \\
\hline WA $f y u A 2$ & - & - & ++ \\
\hline
\end{tabular}

*See also Fig. 7 for GFP fluorescence intensity.

† See also Fig. 8 for halo diameter. 


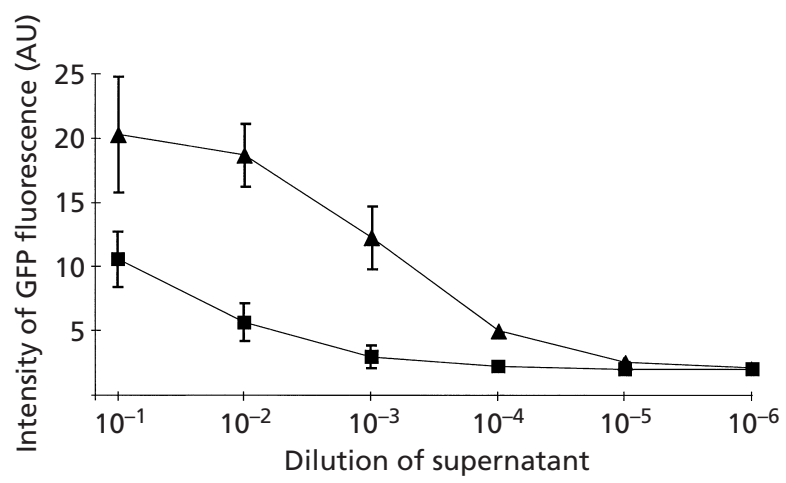

Fig. 6. Fe-Ybt/fyuA-gfp reporter assay: GFP fluorescence (arbitrary units) of $Y$. enterocolitica WA-CS irp1::Kan ${ }^{r}$ (pCJFY5G3) (reporter strain) grown in NBD medium supplemented with culture supernatants of WA-C (A) and WA fyuA2 (ם). Culture supernatants were diluted $\left(10^{-1}-10^{-6}\right)$ with fresh NBD prior to cultivation of the reporter strain. GFP fluorescence was measured after $24 \mathrm{~h}$ growth. Graphs represent the mean of three measurements. Standard deviations are indicated by error bars.

sequence similarities to the permease AmpG, may be involved in regulation of $\mathrm{Ybt}$ biosynthesis.

As a first approach we investigated Ybt production of WA-C and of transport mutants by testing NBD culture supernatants of the corresponding strains for growth support of the indicator strain WA-CS $\operatorname{irp} 1:: \operatorname{Kan}^{\mathrm{r}}$ (disrupted biosynthesis of $\mathrm{Ybt}$ ) seeded in CDM-H agar. As shown in Table 4, NBD culture supernatants of WAC, WA-C $\Delta i r p 6, i r p 7$, WA-C $\Delta i r p 6$, WA-C $\Delta i r p 7$, WA-CS irp7:: $\operatorname{Kan}^{\mathrm{r}}$, WA-CS $\operatorname{irp} 8:: \mathrm{Kan}^{\mathrm{r}}$ and WA-CS $\Delta i r p 6$,irp7, irp 8:: $\operatorname{Kan}^{\mathrm{r}}$ grown in iron-deficient NBD medium were able to feed the indicator strain, whereas the supernatant of WA-CS $\Delta \operatorname{irp} 6, \operatorname{irp} 7, \operatorname{irp} 1:: \operatorname{Kan}^{\mathrm{r}}$ did not support the growth as expected. Surprisingly, the NBD supernatant of WA fyuA2 was also not able to feed significantly WACS irp1::Kan ${ }^{\mathrm{r}}$.

Different Fe-Ybt concentrations of WA-C and WA fyuA2 supernatants could be determined using the Fe-Ybt-sensitive $f y u A-g f p$ reporter strain WA-CS irp1:: $\operatorname{Kan}^{\mathrm{r}}(\mathrm{pCJFY} 5 \mathrm{G} 3)$. GFP fluorescence intensitiy of the reporter strain is induced in a Fe-Ybt concentrationdependent manner. Comparison of the fluorescence intensity/supernatant dilution curves showed that WAC supernatant contained approximately 100 -fold more activity in $f y u A-g f p$ induction than supernatant of strain WA fyuA2 (Fig. 6). These different activities can be attributed to the different $\mathrm{Fe}-\mathrm{Ybt}$ concentration in culture supernatants.

In a second approach, auto-induction of $f y u A-g f p$ expression was tested for WA-C and the various transporter mutants harbouring pCJFY5G3 after growth in NB and NBD medium, respectively. NBgrown strains showed low background fluorescence whereas growth in NBD medium (ferrous iron

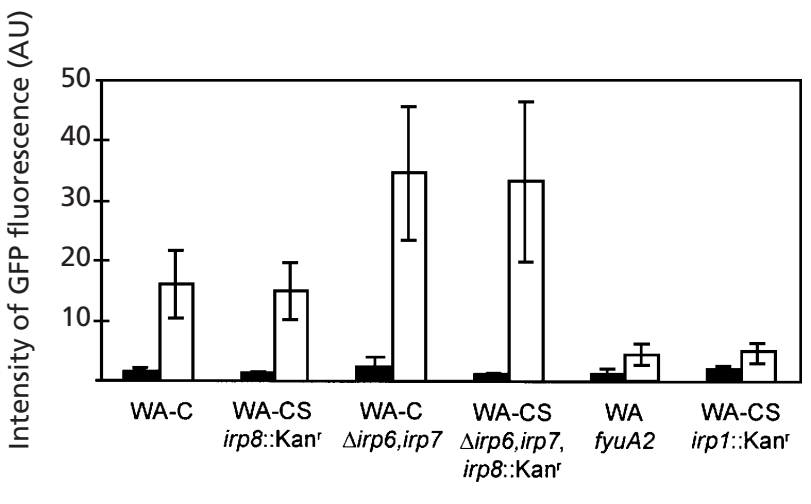

Fig. 7. GFP fluorescence (arbitrary units) of pCJFY5G3-carrying $Y$. enterocolitica strains: WA-CS; WA-CS irp8:: Kan ${ }^{r}$; WA-C Dirp6,irp7; WA-CS $\Delta$ irp6,irp7 irp8::Kan' ${ }^{r}$; WA fyuA2; and WA-CS irp 1:: $\mathrm{Kan}^{\mathrm{r}}$. Solid bars represent GFP fluorescence of the strains in NB, open bars fluorescence in NBD medium. Standard deviations are indicated by error bars.

\section{$\begin{array}{cccc}\text { WA-C } & \text { WA-CS } \\ \text { irp8::Kan } & \text { WA fyuA2 } & \text { WA-C } \\ \text { Dirp6,irp7 }\end{array}$}

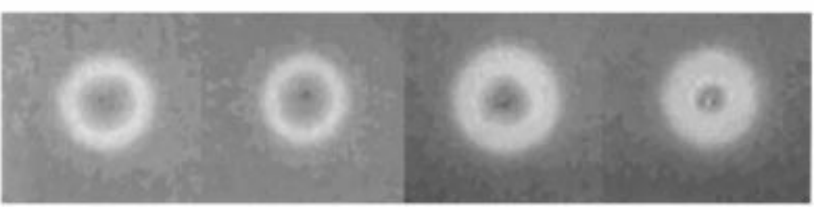

Fig. 8. CAS siderophore indicator agar plate showing haloproducing $Y$. enterocolitica WA-C, WA-CS irp8:: Kan', WA fyuA2 and WA-C $\Delta$ irp6,irp7.

derepression) resulted in bright fluorescing bacteria for WA-C, irp6,irp7 and irp8 mutants but not for fyuA and irp1 mutants (Fig. 7, Table 4). The irp6,irp7 mutant showed twofold higher induction of $f y u-g f p$ in comparison to the parental strain WA-C. irp 8 mutation did not contribute to $f y u A-g f p$ expression.

Taken together the cross-feeding results (Ybt production) are in line with the fyuA-reporter results in so far as irp6/irp7 mutations lead to upregulation whereas $f y u A$ mutation leads to downregulation of Ybt production and $f y u A-g f p$ expression. Thus, the outermembrane receptor FyuA appears to be essential for upregulation of $\mathrm{Ybt}$ biosynthesis and $f y u A$ expression under these growth conditions.

In a third set of experiments Ybt production of WA-C and mutants was checked by using CAS-siderophore indicator agar (Fig. 8, Table 4). All strains producing Ybt in NBD were also able to produce orange haloes around colonies grown on CAS agar. Interestingly, the halo diameter with respect to colony size of irp6/irp7 mutants was larger (indicating hyperproduction of $\mathrm{Ybt}$ ) than those of the parental strain WA-C or irp8 mutant. 


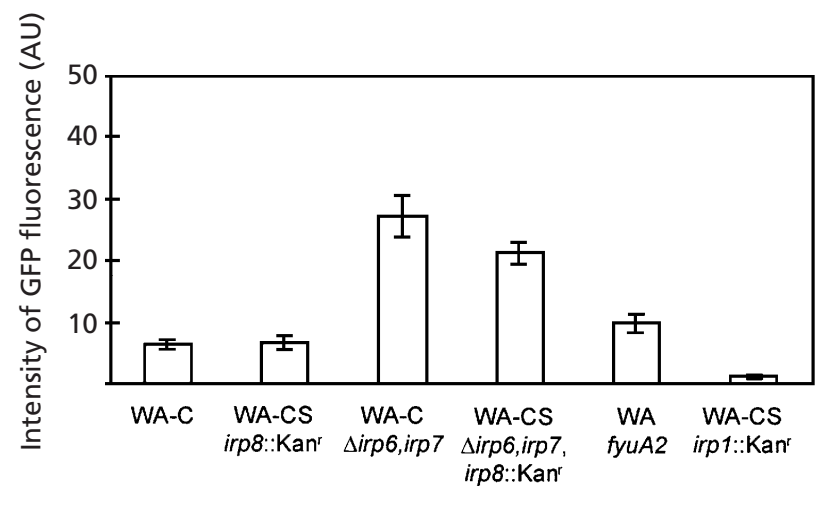

Fig. 9. GFP fluorescence (arbitrary units) of pCJFY5G3-carrying $Y$. enterocolitica strains: WA-CS; WA-CS irp8::Kan'; WA-C Dirp6,irp7; WA-CS $\Delta$ irp6,irp7, irp8:: $\mathrm{Kan}^{\mathrm{r}}$; WA fyuA2; and WA-CS irp $1:: \mathrm{Kan}^{r}$. All strains were grown on CAS siderophore indicator agar for $24 \mathrm{~h}$. Standard deviations are indicated by error bars.

Table 5. GFP fluorescence intensity of WA fyuA2 ( $p C J F Y 5 G 3$ ) grown for $24 \mathrm{~h}$ in NBD medium plus various supplements

\begin{tabular}{|lc|}
\hline Supplement* & $\begin{array}{c}\text { GFP fluorescence } \\
\text { (arbitrary units) } \dagger\end{array}$ \\
\hline None & $5 \cdot 5(1 \cdot 4)$ \\
$\mathrm{HDTMA}, \mathrm{CAS}, \mathrm{FeCl}_{3}$ & $15 \cdot 1(3 \cdot 8)$ \\
$\mathrm{CAS}, \mathrm{FeCl}_{3}$ & $9 \cdot 4(1 \cdot 6)$ \\
$\mathrm{CAS}$ & $5 \cdot 5(0 \cdot 7)$ \\
Ferric citrate & $9 \cdot 7(0 \cdot 8)$ \\
\hline
\end{tabular}

*HDTMA, $200 \mu \mathrm{M}$; CAS, 60.5 mg l-1; $\mathrm{FeCl}_{3}, 10 \mu \mathrm{M}$; ferric citrate, $10 \mu \mathrm{M}$.

† Standard deviations in parentheses.

Strain WA-CS $\operatorname{irp} 1:: \operatorname{Kan}^{\mathrm{r}}$ was CAS negative as expected. However, the $f y u A$ mutant, which was negative in cross-feeding (culture supernatant), also developed a large halo (CAS positive). This unexpected phenotype of WA fyuA2 prompted us to check also $f y u A-g f p$ upregulation of the strains grown on CAS agar. WA-C and transport mutants including $f y u A$ mutant showed upregulation of the $f y u A-g f p$ reporter (Fig. 9). Obviously CAS agar contains substances which are able to upregulate $f y u A-g f p$ in WA fyuA2 (pCJFY5G3). For this reason WA fyuA2(pCJFY5G3) was incubated for $24 \mathrm{~h}$ in NBD medium supplemented with components of CAS agar such as HDTMA-CAS-FeCl ${ }_{3}, \mathrm{CAS}-\mathrm{FeCl}_{3}$ or CAS and additionally with ferric citrate. As shown in Table 5 the supplement consisting of the cationic detergent HDTMA, the ferric iron indicator dye CAS and $\mathrm{FeCl}_{3}$ was able to induce $f y u A-g f p$ upregulation in the $f y u A$ mutant. A less strong inductive effect was also observed with CAS- $\mathrm{FeCl}_{3}$ and ferric citrate. Addition of HDTMA alone $(20 \mu \mathrm{M}$ or $200 \mu \mathrm{M})$ to NBD culture turned out to be harmful for yersiniae (bactericidal effect). In conclusion, $f y u A-g f p$ in the WA $f y u A 2$ transport mutant can be upregulated in the presence of CAS-agar supplements, provided that $\mathrm{Ybt}$ biosynthesis genes are not impaired. This result indicates that FyuA is not absolutely required for upregulation of Ybt biosynthesis in the presence of complexed ferric iron and a cationic detergent.

\section{DISCUSSION}

In this study we investigated the gene cluster $\operatorname{irp} 6,7,8$ of $\mathrm{Y}$. enterocolitica WA-C with respect to Fe-Ybt utilization in yersiniae and E. coli, mouse virulence and Fe-Ybt-transport-dependent control of Ybt production and $f y u A-g f p$ reporter gene expression in Y. enterocolitica.

According to the known high sequence homology between irp6,7 of Yen HPI and $y b t P, Q$ of Yps HPI we could confirm that gene products Irp6 and Irp7 are involved in $\mathrm{Fe}-\mathrm{Ybt}$ transport through the cytoplasmic membrane (Fig. 2a) (Fetherston et al., 1999). Consistent with the hypothesis that Fe-Ybt uptake is required for survival and replication of Yersinia in mice the irp6,irp7 mutant was highly attenuated in mouse virulence in spite of Ybt production (Table 3).

The irp8 gene downstream of irp7 exhibits $99 \%$ homology to $y b t X$ of $Y$. pestis and significant homology to $\operatorname{ampG}$, which encodes a muropeptide permease (AmpG) in Gram-negative bacteria (Lindquist et al., 1993). Similar to AmpG we also could not identify the typical consensus sequence EAAXXXG (EAA-loop) of inner membrane proteins from periplasmic-bindingprotein-dependent transport (PBT) systems within Irp8 (Braun et al., 1998; Boos \& Lucht, 1996). Nevertheless, it could be possible that Irp8 functions as an innermembrane permease for Fe-Ybt in the context of Ybtmediated signal transduction, as is known for AmpG in $\beta$-lactamase regulation (Jacobs et al., 1997). However, disruption of irp8 did not affect (i) Ybt utilization or production (similar to YbtX of Y. pestis; Fetherston et al., 1999), (ii) Fe-Ybt-dependent fyuA-gfp expression in WA-CS $\operatorname{irp} 8:: \operatorname{Kan}^{\mathrm{r}}$ (pCJFY5G3), or (iii) mouse virulence potential of Y. enterocolitica. Thus, the function of Irp8 remains unclear.

We examined whether the capability to utilize Fe-Ybt can be transferred into E. coli H1884 and non-pathogenic Y. enterocolitica NF-O (both strains are HPInegative) by introduction of the transport genes fyuA, irp6 and irp7. Surprisingly, the E. coli recipient, but not the Y. enterocolitica NF-O recipient, showed growth support by addition of Fe-Ybt (Fig. 2b, c). Immunoblotting (Fig. 3), RT-PCR (Fig. 4) and pesticin assay revealed $i r p 6$, irp7 and $f y u A$ expression as well as functional FyuA in both strains, Y. enterocolitica NF-O and E. coli H1884. To explain the strains' discrepancy in Fe-Ybt uptake we may assume that E. coli H1884 but not Y. enterocolitica NF-O is able to supply a periplasmic binding protein for $\mathrm{Fe}-\mathrm{Ybt}$ transport and/or a 
Fe-Ybt dissociation factor, although we cannot exclude other possibilities. Nevertheless this conclusion could be of significance with respect to evolution of new pathotypes of microbes by horizontal gene transfer of the HPI. Recently, it was shown that the Yps HPI is widely distributed within the family Enterobacteriaceae, in particular in certain pathotypes of E. coli (Schubert et al., 1998). Considering horizontal transfer of the HPI, it is conceivable that the only recipients that would benefit from the HPI by improved iron provision are those which already carry genes complementing the Fe-Ybt transport/utilization system.

The Fe-Ybt transport mutants of yersiniae were also studied for Fe-Ybt-dependent regulation, Ybt biosynthesis and Fe-Ybt utilization. The current model (Fig. 5) of core gene regulation includes two transcriptional regulators: (i) ferrous iron surplus in the cytosol results in gene repression by the $\mathrm{Fe}^{2+}-\mathrm{Fur}$ complex and ferrous iron depletion in derepression (e.g. by $\alpha, \alpha^{\prime}$-dipyridyl), (ii) the transcriptional activator YbtA is an AraC-like protein which is activated by binding FeYbt and thus can upregulate the $i r p / f y u A$ gene cluster (Fetherston et al., 1996). According to this model the $f y u A-g f p$ reporter gene was upregulated because of $\mathrm{Fe}-$ Ybt uptake in the parental strain WA-C and in the irp8 mutant when grown in iron-depleted medium (Furderepressed, Fe-Ybt-induced). Under the same growth conditions the $f y u A-g f p$ expression was surprisingly also upregulated in the transport mutant WA-C $\Delta$ irp6,irp7 whereas it was downregulated in WA fyuA2 (Fig. 7). Corresponding to the Fe-Ybt transport defects of the irp6,irp7 and fyuA mutants one would expect Fur derepression and lack of $\mathrm{Fe}-\mathrm{Ybt} / \mathrm{YbtA}$-mediated activation of $f y u A-g f p$. As Irp8 might be involved in weak transport of Fe-Ybt through the cytoplasmic membrane just sufficient for upregulation of $f y u A-g f p$ but insufficient for feeding, an irp6,irp7,irp 8 triple mutant was included; it showed no differences from the irp6,irp7 double mutant. According to these results $f y u A-g f p$ upregulation requires FyuA for $\mathrm{Fe}-\mathrm{Ybt}$ transport through the outer membrane or for Fe-Ybt-mediated signalling through FyuA. It is reasonable that after passing the FyuA pore Fe-Ybt is able (i) to permeate non-specifically through the cytoplasmic membrane and to activate YbtA or (ii) to use the recently described TonB-independent cytoplasmic membrane iron-transport systems $y f e A B C D$ of $Y$. pestis and $y f u A B C D$ of $Y$. enterocolitica, respectively (Bearden et al., 1998; Saken et al., 2000). In contrast to the cytoplasmic membrane, the outer membrane should be impermeable for $\mathrm{Fe}-\mathrm{Ybt}$ and thus $f y u A$ gene induction be abolished in the $f y u A$ mutant.

$f y u A-g f p$ reporter studies in NBD medium (Fig. 7) and cross-feeding results indicate high Ybt production by the irp6,irp7 mutant and no or low Ybt production of the fyuA mutant. However, results from CAS agar showed high Ybt production and $f y u A-g f p$ upregulation for both $f y u A$ and irp6,irp7 mutants (Fig. 9). As CAS agar contains the cationic detergent HDTMA and ferric iron bound to CAS, it is reasonable to assume that this detergent renders the outer membrane of $Y$. enterocolitica permeable for $\mathrm{Fe}-\mathrm{Ybt}$ or Fe-CAS. This hypothesis could be verified in so far as HDTMA-CAS$\mathrm{FeCl}_{3}$ turned out to be an effective inducer of $f y u A-g f p$ expression in NBD broth. Thus, in spite of a lack of FyuA, sufficient Fe-Ybt may enter the periplasm and subsequently the cytoplasm by Irp6/Irp7 for activation of YbtA under CAS agar growth conditions. These results do not rule out the possibility that besides Fe-Ybt transport-mediated $f y u A$ gene expression, FyuA signalling may play a role as has been described for ferric citrate-mediated iron transport (FecA-FecR-FecI cascade) (Braun et al., 1998). Interestingly, it has been demonstrated that the outer membrane permeability to hydrophobic agents is much higher for Y. pestis than for Y. enterocolitica (Bengoechea et al., 1998). If this is also correct for Fe-Ybt we would expect Ybt-dependent upregulation of the $p s n$-reporter gene in Y. pestis psn mutant but not of the $f y u A$-reporter gene in Y. enterocolitica fyuA mutant ( $f y u A$ is orthologous to $p s n$ of $Y$. pestis) in detergent-free culture medium. These apparently inconsistent results have been addressed recently (Perry et al., 1999).

Taken together this functional analysis of irp6-8 and $f y u A$ has revealed the following interesting new findings.

(i) For the first time it has been demonstrated that irp8 does not contribute to mouse virulence.

(ii) fyuA or irp6,7,8 expression is not absolutely required for Fe-Ybt-induced upregulation of $f y u A-g f p$, which indicates that these genes are probably not involved in a putative Fe-Ybt-mediated signalling pathway.

(iii) The irp6,7/fyuA gene cluster is sufficient to mediate Fe-Ybt utilization in E. coli but not in an avirulent $Y$. enterocolitica NF-O, BG IA strain, indicating that additional genes are required for this phenotype.

(iv) The CAS siderophore indicator supplement in CAS agar is able to induce $\mathrm{Ybt}$ biosynthesis and $f y u A$ gene expression independent of the presence of the outermembrane siderophore receptor. This should be considered by monitoring siderophore production of Gram-negative bacteria.

\section{ACKNOWLEDGEMENTS}

This study was supported by a grant from the Deutsche Forschungsgemeinschaft to J.H. (HE 1297/8-2) and to C. J. (Graduiertenkolleg 'Infektion und Immunität': GRK 303). We thank V. Kempf and E. Igwe for excellent help in mice infection, R. Reissbrodt (Wernigerode, Germany) for purified yersiniabactin, and A. Iwobi and C. Nölting for critical reading of the manuscript.

\section{REFERENCES}

Bäumler, A. J. \& Hantke, K. (1992). Ferrioxamine uptake in Yersinia enterocolitica: characterization of the receptor protein FoxA. Mol Microbiol 6, 1309-1321.

Bearden, S. W., Fetherston, J. D. \& Perry, R. D. (1997). Genetic 
organization of the yersiniabactin biosynthetic region and construction of avirulent mutants in Yersinia pestis. Infect Immun 65, 1659-1668.

Bearden, S. W., Staggs, T. M. \& Perry, R. D. (1998). An ABC transporter system of Yersinia pestis allows utilization of chelated iron by Escherichia coli SAB11. J Bacteriol 180, 1135-1147.

Bengoechea, J. A., Brandenburg, K., Seydel, U., Diaz, R. \& Moriyon, I. (1998). Yersinia pseudotuberculosis and Yersinia pestis show increased outer membrane permeability to hydrophobic agents which correlates with lipopolysaccharide acylchain fluidity. Microbiology 144, 1517-1526.

Boos, W. \& Lucht, J. M. (1996). Periplasmic binding proteindependent ABC transporters. In Escherichia coli and Salmonella: Cellular and Molecular Biology, 2nd edn, pp. 1175-1209. Edited by F. C. Neidhardt and others. Washington, DC: American Society for Microbiology.

Braun, V., Hantke, K. \& Koster, W. (1998). Bacterial iron transport : mechanisms, genetics, and regulation. Metal Ions Biol Syst 35, 67-145.

Brubaker, R. R. (1991). Factors promoting acute and chronic diseases caused by yersiniae. Clin Microbiol Rev 4, 309-324.

Buchrieser, C., Rusniok, C., Frangeul, L., Couve, E., Billault, A. \& Kunst, F. (1999). The 102-kilobase pgm locus of Yersinia pestis: sequence analysis and comparison of selected regions among different Yersinia pestis and Yersinia pseudotuberculosis strains. Infect Immun 67, 4851-4861.

Carniel, E., Guiyoule, A., Guilvout, I. \& Mercereau Puijalon, O. (1992). Molecular cloning, iron-regulation and mutagenesis of the irp2 gene encoding HMWP2, a protein specific for the highly pathogenic Yersinia. Mol Microbiol 6, 379-388.

Carniel, E., Guilvout, I. \& Prentice, M. (1996). Characterization of a large chromosomal high-pathogenicity island in biotype $1 \mathrm{~B}$ Yersinia enterocolitica. J Bacteriol 178, 6743-6751.

Chang, A. C. \& Cohen, S. N. (1978). Construction and characterization of amplifiable multicopy DNA cloning vehicles derived from the P15A cryptic miniplasmid. J Bacteriol 134, 1141-1156.

Earhart, C. F. (1996). Uptake and metabolism of iron and molybdenum. In Escherichia coli and Salmonella: Cellular and Molecular Biology, 2nd edn, pp. 1075-1090. Edited by F. C. Neidhardt and others. Washington, DC: American Society for Microbiology.

Fetherston, J. D., Bearden, S. W. \& Perry, R. D. (1996). YbtA, an AraC-type regulator of the Yersinia pestis pesticin/yersiniabactin receptor. Mol Microbiol 22, 315-325.

Fetherston, J. D., Bertolino, V. J. \& Perry, R. D. (1999). YbtP and YbtQ: two ABC transporters required for iron uptake in Yersinia pestis. Mol Microbiol 32, 289-299.

Flossmann, K. D., Grajetzki, C. \& Rosner, H. (1985). Nachweis von Eisen-Transport-Aktivität in Pasteurella multocida-Kulturen. J Basic Microbiol 25, 559-567.

Friedmann, A. M., Long, S. R., Brown, S. E., Buikema, W. J. \& Ausubel, F. M. (1982). Construction of a broad-host-range cosmid cloning vector and its use in the genetic analysis of Rhizobium mutants. Gene 18, 289-296.

Galan, J. E., Ginocchio, C. \& Costeas, P. (1992). Molecular and functional characterization of the Salmonella typhimurium invasion gene inv $A$ : homology of InvA to members of a new protein family. J Bacteriol 17, 4338-4349.

Gehring, A. M., DeMoll, E., Fetherston, J. D., Mori, I., Mayhew, G. F. \& Blattner, F. R. (1998). Iron acquisition in plague: modular logic in enzymic biogenesis of yersiniabactin by Yersinia pestis. Chem Biol 5, 573-586.
Guzman, L. M., Belin, D., Carson, M. J. \& Beckwith, J. (1995). Tight regulation, modulation, and high-level expression by vectors containing the arabinose $\mathrm{p}_{\mathrm{BAD}}$ promoter. J Bacteriol 177, 4121-4130.

Hanahan, D. (1983). Studies on transformation of Escherichia coli with plasmids. J Mol Biol 166, 557-580.

Heesemann, J. (1987). Chromosomal-encoded siderophores are required for mouse virulence of enteropathogenic Yersinia species. FEMS Microbiol Lett 48, 229-233.

Heesemann, J. \& Laufs, R. (1983). Construction of a mobilizable Yersinia enterocolitica virulence plasmid. J Bacteriol 155, 761-767.

Heesemann, J., Gross, U., Schmidt, N. \& Laufs, R. (1986). Immunochemical analysis of plasmid-encoded proteins released by enteropathogenic Yersinia sp. grown in calcium-deficient media. Infect Immun 54, 561-567.

Heesemann, J., Hantke, K., Vocke, T., Saken, E., Rakin, A., Stojiljkovic, I. \& Berner, R. (1993). Virulence of Yersinia enterocolitica is closely associated with siderophore production, expression of an iron-repressible outer membrane polypeptide of $65000 \mathrm{Da}$ and pesticin sensitivity. Mol Microbiol 8, 397-408.

Hu, P. C., Yang, G. C. \& Brubaker, R. R. (1972). Specificity, induction, and absorption of pesticin. J Bacteriol 112, 212-219.

Jacobi, C. A. (1999). Analyse von Pathogenitätsfaktoren von Yersinia enterocolitica mit den Reportergenen GFP und Luziferase. $\mathrm{PhD}$ thesis, Universität Würzburg, Germany.

Jacobi, C. A., Roggenkamp, A., Rakin, A., Zumbihl, R., Leitritz, L. \& Heesemann, J. (1998). In vitro and in vivo expression studies of yopE from Yersinia enterocolitica using the $g f p$ reporter gene. Mol Microbiol 30, 865-882.

Jacobs, C., Frere, J. M. \& Normark, S. (1997). Cytosolic intermediates for cell wall biosynthesis and degradation control inducible beta-lactam resistance in Gram-negative bacteria. Cell 88, 823-832.

Kaniga, K., Delor, I. \& Cornelis, G. R. (1991). A wide-host-range suicide vector for improving reverse genetics in Gram-negative bacteria: inactivation of the blaA gene of Yersinia enterocolitica. Gene 109, 137-141.

Laemmli, U. K. (1970). Cleavage of structural proteins during the assembly of the head of bacteriophage T4. Nature 227, 680-685.

Lindquist, S., Weston-Hafer, K., Schmidt, H., Pul, C., Korfmann, G., Erickson, J., Sanders, C., Martin, H. H. \& Normark, S. (1993). AmpG, a signal transducer in chromosomal $\beta$-lactamase induction. Mol Microbiol 9, 703-715.

Miller, V. L. \& Mekalanos, J. J. (1988). A novel suicide vector and its use in construction of insertion mutations: osmoregulation of outer-membrane proteins and virulence determinants in Vibrio cholerae requires toxR. J Bacteriol 170, 2575-2583.

Pelludat, C., Rakin, A., Jacobi, C. A., Schubert, S. \& Heesemann, J. (1998). The yersiniabactin biosynthetic gene cluster of Yersinia enterocolitica: organization and siderophore-dependent regulation. J Bacteriol 180, 538-546.

Perry, R. D. \& Fetherston, J. D. (1997). Yersinia pestis - etiologic agent of plague. Clin Microbiol Rev 10, 35-66.

Perry, R. D., Balbo, P. B., Jones, H. A., Fetherston, J. D. \& DeMoll, E. (1999). Yersiniabactin from Yersinia pestis: biochemical characterization of the siderophore and its role in iron transport and regulation. Microbiology 145, 1181-1190.

Rakin, A. \& Heesemann, J. (1995). Yersiniabactin/pesticin receptor: a component of an iron uptake system of highly pathogenic Yersinia. Contrib Microbiol Immunol 13, 244-247. 
Rakin, A., Saken, E., Harmsen, D. \& Heesemann, J. (1994). The pesticin receptor of Yersinia enterocolitica: a novel virulence factor with dual function. Mol Microbiol 13, 253-263.

Rakin, A., Urbitsch, P. \& Heesemann, J. (1995). Evidence for two evolutionary lineages of highly pathogenic Yersinia species. $J$ Bacteriol 177, 2292-2298.

Rakin, A., Noelting, C., Schubert, S. \& Heesemann, J. (1999a). Common and specific characteristics of the high-pathogenicity island of Yersinia enterocolitica. Infect Immun 67, 5265-5274.

Rakin, A., Schubert, S., Pelludat, C., Brem, D. \& Heesemann, J. (1999b). The high-pathogenicity island of yersiniae. In Pathogenicity Islands and Other Mobile Virulence Elements, pp. 77-90. Edited by J. B. Kaper \& J. Hacker. Washington, DC: American Society for Microbiology.

Saken, E., Rakin, A. \& Heesemann, J. (2000). Molecular characterization of a novel siderophore-independent iron transport system in Yersinia. Int J Med Microbiol 290, 51-60.

Sauer, M., Hantke, K. \& Braun, V. (1990). Sequence of the fhuE outer-membrane receptor gene of Escherichia coli K-12 and properties of mutants. Mol Microbiol 4, 427-437.

Schubert, S., Rakin, A., Karch, H., Carniel, E. \& Heesemann, J. (1998). Prevalence of the "high-pathogenicity island" of Yersinia species among Escherichia coli strains that are pathogenic to humans. Infect Immun 66, 480-485.

Schubert, S., Fischer, D. \& Heesemann, J. (1999). Ferric enterochelin transport in Yersinia enterocolitica: molecular and evolutionary aspects. J Bacteriol 181, 6387-6395.
Schubert, S., Cuenca, S., Fischer, D. \& Heesemann, J. (2000). Highpathogenicity island of Yersinia pestis in Enterobacteriaceae isolated from blood cultures and urine samples: prevalence and functional expression. J Infect Dis 182, 1268-1271.

Schwyn, B. \& Neilands, J. B. (1987). Universal chemical assay for the detection and determination of siderophores. Anal Biochem $160,47-56$.

Simon, R., Priefer, U. \& Pühler, A. (1988). A broad host range mobilization system for in vivo genetic engineering: transposon mutagenesis in Gram-negative bacteria. Biotechnology 1, 784-785.

Skorupski, K. \& Taylor, R. K. (1996). Positive selection vectors for allelic exchange. Gene 169, 47-52.

Staggs, T. M., Fetherston, J. D. \& Perry, R. D. (1994). Pleiotropic effects of a Yersinia pestis fur mutation. J Bacteriol 176, 7614-7624.

Tabor, S. \& Richardson, C. C. (1985). A bacteriophage T7 RNA polymerase/promoter system for controlled exclusive expression of specific genes. Proc Natl Acad Sci U S A 82, 1074-1078.

Une, T. \& Brubaker, R. R. (1984). In vivo comparison of avirulent $\mathrm{Vwa}^{-}$and $\mathrm{Pgm}^{-}$or $\mathrm{Pst}^{\mathrm{r}}$ phenotypes of yersiniae. Infect Immun 43, 895-900.

Received 11 September 2000; revised 22 December 2000; accepted 7 February 2001. 